\title{
Analysis of Estimation Errors in Rotor Position for a Sensorless Control System Using a PMSM
}

\author{
Yongsoon Park ${ }^{*}$, Seung-Ki Sul ${ }^{\dagger}$, Jun-Keun $\mathrm{Ji}^{* *}$, and Young-Jae Park ${ }^{* * *}$ \\ $\dagger^{* *}$ Dept. of Electrical Eng. and Computer Science, Seoul National University, Seoul, Korea \\ ${ }^{* *}$ Dept. of Electrical Eng., Soonchunhyang University, Choongnam, Korea \\ ${ }^{* * *}$ Digital Media and Communication R\&D Center, Samsung Electronics Co., Ltd., Suwon, Korea
}

\begin{abstract}
In a sensorless control system with a Permanent Magnet Synchronous Motor (PMSM), the angular position of the rotor flux can be estimated by a voltage equation. However, the estimated angle may be inaccurate due to various causes. In this paper, it was comprehensively analyzed how various causes affect the angle error. As a result of the analysis, an error equation intuitively describing these relationships was derived. The parameter errors of a PMSM and the non-ideal properties of the driving system were identified as error-causing factors. To demonstrate the validity of the error equation, PMSMs were tested at various operating points. The variations in angle errors could be well explained with the error equation.
\end{abstract}

Key words: Angle error, Permanent magnet synchronous motor, Sensorless control

\section{INTRODUCTION}

Position sensorless control methods based on the voltage equation of PMSMs are commonly used in the medium to high speed operating range where the back Electromotive Force (EMF) is large enough [1]-[4]. However, even in this speed range, the sensorless performance may be degraded for many reasons. These degradations can occur if the perceived system for a sensorless design is different than the practical system [5]-[7]. As an example, an estimated rotor angle might be inaccurate due to this kind of discrepancy. What was worse, this inaccuracy may lead to instability of the system.

Theoretically, if the error between the estimated angle and the actual angle is detected every instant, the rotor angle can be accurately estimated. However, the angle error cannot be measured because no position sensor is used. Therefore, some indirect effort to obtain the angle error, which is defined as (1), is required in sensorless control systems [1]-[4].

$$
\theta_{\mathrm{d}}=\theta-\hat{\theta} .
$$

Manuscript received Mar. 5, 2012 ; revised Jul. 5, 2012

Recommended for publication by Associate Editor Jung-Ik Ha.

†Corresponding Author: sulsk@plaza.snu.ac.kr

Tel: +82-2-880-7641, Fax: +82-2-878-1452, Seoul Nat'1 University

*Dept. of Electrical Eng. and Computer Science, Seoul National University, Korea

${ }^{* *}$ Dept. of Electrical Eng. Soonchunhyang University, Korea

*** DMC R\&D center, Samsung Electronics Co., Ltd., Korea
The hat ' ' over a variable represents the estimated value. In this paper, an estimated value may be a practical or a nominal value used for control.

Angle information is defined as being proportional to the angle error. This information can be obtained by a voltage equation describing the internal voltages of a PMSM in the rotor reference frame. However, unpredictable errors might be included in the angle information due to discrepancies.

One category of discrepancy is related to the parameters of a PMSM that are seen as coefficients in a voltage equation. If these coefficients are not correct, the internal voltages of the PMSM cannot be accurately determined by the voltage equation. Then, the angle information is incorrect if it is obtained by using the incorrect voltage equation. In motor driving, some constant values are normally used for control while the actual counterparts can vary depending on the driving conditions. That is, due to these parameter errors, the angle estimation can be distorted.

The other category of discrepancy can be related to the driving system of a PMSM. In general, the actual outputs of a Voltage Source Inverter (VSI) are not measured. However, these outputs are needed for any calculations using the voltage equation. Thus, the voltage references are used for the calculations instead of the actual output voltages. If the references are different than the actual outputs, the angle information is incorrectly obtained. For instance, the nonlinearity of the inverter may lead to voltage differences 
[9]-[12], and the digital delay of the control system can intensify these differences [13].

Attempts to consider the factors causing angle errors have been performed intermittently [5]-[7]. However, a comprehensive discussion considering all of the factors has not been developed. In this paper, the factors, including the parameters of a PMSM and the non-idealities of the driving system, affecting the angle error are analyzed all at once. The sensorless control method in [1] can be selected for analysis due to its simplicity.

The analysis describing the angle error can be summarized with an intuitive equation that consists of the error-causing factors. To insure the validity of the error equation, PMSMs were tested in practical systems. Each term in the error equation was examined under careful considerations.

\section{ERROR EQUATION FOR ANGLE ESTIMATION}

\section{A. Generalized Factors Causing Angle Errors}

It is worth discussing how a certain factor leads to angle errors. A type 2 system, which is the simplest structure for achieving a zero-steady-state error to a ramp input, is shown in Fig. 1. The type 2 system's open-loop transfer function is given as $\mathrm{G}(\mathrm{s})$ :

$$
\mathrm{G}(\mathrm{s})=\frac{\mathrm{k}_{\mathrm{pa}} \cdot \mathrm{s}+\mathrm{k}_{\mathrm{ia}}}{\mathrm{s}^{2}}
$$

The angle error can be derived from Fig. 1 as:

$$
\theta^{\mathrm{s}}-\hat{\theta}^{\mathrm{s}}=\theta^{\mathrm{s}}-\frac{\mathrm{G}(\mathrm{s})}{1+\mathrm{G}(\mathrm{s})} \theta^{\mathrm{s}}=\frac{1}{1+\mathrm{G}(\mathrm{s})} \cdot \theta^{\mathrm{s}}
$$

where the superscript ' $\mathrm{s}$ ' represents that the variable is in Laplace domain.

When the rotating speed of a PMSM is constant, an actual angle $\theta^{\mathrm{s}}$ presents a ramp variation because it is an integral of that speed. As derived in (4), the type 2 system shows a zero-steady-state error in response to a ramp as expected:

$$
\lim _{t \rightarrow \infty}[\theta(\mathrm{t})-\hat{\theta}(\mathrm{t})]=\lim _{s \rightarrow 0} \mathrm{~s} \cdot\left(\theta^{\mathrm{s}}-\hat{\theta}^{\mathrm{s}}\right)=\lim _{s \rightarrow 0} \frac{\mathrm{s}}{1+\mathrm{G}(\mathrm{s})} \cdot \frac{1}{\mathrm{~s}^{2}}=0 .
$$

Therefore, a kind of type 2 system can be applied to a sensorless control system. However, because the actual angle is not measured, only the angle controller, G(s) in Fig. 1, can be exploited, as shown in Fig. 2. That is, the angle information should be indirectly obtained. However, if some errors are incorporated into the information, the estimated angle cannot be converged with the actual one.

Errors in angle information can be generalized by their relationships with the angle error, as shown in Fig. 2. Namely, information errors can be classified into multiplicative and additive errors, which correspond to $\mathrm{k}_{\theta}^{\mathrm{s}}$ and $\mathrm{E}_{\theta}^{\mathrm{s}}$, respectively. From Fig. 2, (5) can be derived and rewritten as (6):

$$
\mathrm{k}_{\theta}^{\mathrm{s}} \cdot\left\{\left(\theta^{\mathrm{s}}-\hat{\theta}^{\mathrm{s}}\right)+\mathrm{E}_{\theta}^{\mathrm{s}}\right\} \cdot \frac{\mathrm{k}_{\mathrm{pa}} \cdot \mathrm{s}+\mathrm{k}_{\mathrm{ia}}}{\mathrm{s}^{2}}=\hat{\theta}^{\mathrm{s}}
$$

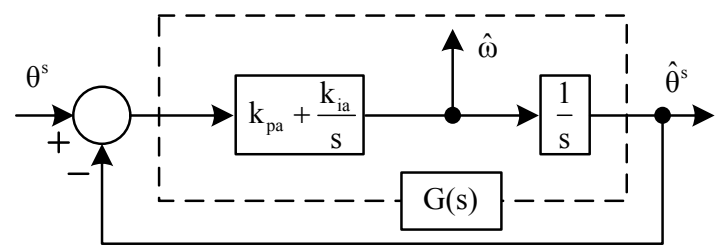

Fig. 1. Type 2 system.

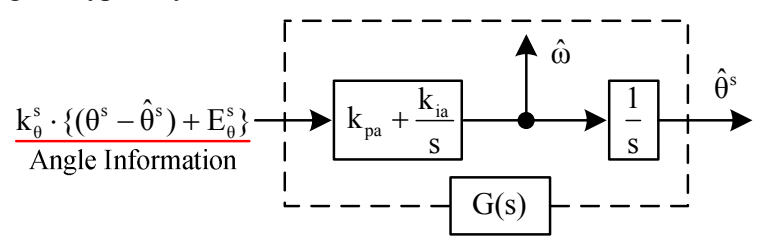

Fig. 2. Angle controller in a sensorless control system.

$$
\hat{\theta}^{\mathrm{s}}=\frac{\mathrm{k}_{\theta}^{\mathrm{s}} \mathrm{k}_{\mathrm{pa}} \cdot \mathrm{s}+\mathrm{k}_{\theta}^{\mathrm{s}} \mathrm{k}_{\mathrm{ia}}}{\mathrm{s}^{2}+\mathrm{k}_{\theta}^{\mathrm{s}} \mathrm{k}_{\mathrm{pa}} \cdot \mathrm{s}+\mathrm{k}_{\theta}^{\mathrm{s}} \mathrm{k}_{\mathrm{ia}}} \cdot \theta^{\mathrm{s}}+\frac{\mathrm{k}_{\theta}^{\mathrm{s}} \mathrm{k}_{\mathrm{pa}} \cdot \mathrm{s}+\mathrm{k}_{\theta}^{\mathrm{s}} \mathrm{k}_{\mathrm{ia}}}{\mathrm{s}^{2}+\mathrm{k}_{\theta}^{\mathrm{s}} \mathrm{k}_{\mathrm{pa}} \cdot \mathrm{s}+\mathrm{k}_{\theta}^{\mathrm{s}} \mathrm{k}_{\mathrm{ia}}} \cdot \mathrm{E}_{\theta}^{\mathrm{s}} .
$$

The information errors can be modeled as step signals if they are mainly distributed in a low frequency range [15]. Then, from (6), it can be inferred that the effect of the additive error is observed in the steady state whereas that of the multiplicative error is observed only during the transient state. This feature would be similar for impulse errors that are constant values in the Laplace domain. In other words, the additive error is the main factor causing angle errors under normal operation. This is why the additive error is focused on in this paper.

In addition to achieving a zero-steady-state error, the reason why the angle controller in Fig. 2 is applied to angle estimation becomes pronounced when considering (6). Because the transfer functions in (6) are in the form of a low-pass filter, high frequency noises can be substantially filtered out by the angle controller.

To consider more specific effects from information errors, the ramp variation of the rotor angle can be modeled as (7) when the magnitude of the speed is given as $\omega_{\mathrm{m}}$ :

$$
\theta^{\mathrm{s}}=\frac{1}{\mathrm{~s}} \cdot \omega^{\mathrm{s}}=\frac{\omega_{\mathrm{m}}}{\mathrm{s}^{2}}, \text { if } \omega^{\mathrm{s}}=\frac{\omega_{\mathrm{m}}}{\mathrm{s}} .
$$

If (7) is inserted into (6), the estimated speed is derived as (8) in the steady state. That is, the speed can be accurately estimated even if the information errors are considered.

$$
\lim _{t \rightarrow \infty} \hat{\omega}(\mathrm{t})=\lim _{s \rightarrow 0} \mathrm{~s} \cdot \hat{\omega}^{\mathrm{s}}=\lim _{s \rightarrow 0} \mathrm{~s} \cdot\left(\mathrm{s} \hat{\theta}^{\mathrm{s}}\right)=\omega_{\mathrm{m}}=\lim _{t \rightarrow \infty} \omega(\mathrm{t}) .
$$

When each side of (6) is subtracted from the actual angle $\theta^{\mathrm{s}}$, the angle error can be derived as:

$\theta^{\mathrm{s}}-\hat{\theta}^{\mathrm{s}}=\frac{\mathrm{s}^{2}}{\mathrm{~s}^{2}+\mathrm{k}_{\theta}^{\mathrm{s}} \mathrm{k}_{\mathrm{pa}} \cdot \mathrm{s}+\mathrm{k}_{\theta}^{\mathrm{s}} \mathrm{k}_{\mathrm{ia}}} \cdot \theta^{\mathrm{s}}-\frac{\mathrm{k}_{\theta}^{\mathrm{s}} \mathrm{k}_{\mathrm{pa}} \cdot \mathrm{s}+\mathrm{k}_{\theta}^{\mathrm{s}} \mathrm{k}_{\mathrm{ia}}}{\mathrm{s}^{2}+\mathrm{k}_{\theta}^{\mathrm{s}} \mathrm{k}_{\mathrm{pa}} \cdot \mathrm{s}+\mathrm{k}_{\theta}^{\mathrm{s}} \mathrm{k}_{\mathrm{ia}}} \cdot \mathrm{E}_{\theta}^{\mathrm{s}}$.

Based on (7) and (9), the following are derived if the additive and the multiplicative errors are modeled as $\mathrm{E}_{\mathrm{m}} / \mathrm{s}$ and $\mathrm{k}_{\theta} / \mathrm{s}$, respectively:

$$
\lim _{t \rightarrow \infty}[\theta(\mathrm{t})-\hat{\theta}(\mathrm{t})]=\lim _{s \rightarrow 0} \mathrm{~s} \cdot\left(\theta^{\mathrm{s}}-\hat{\theta}^{\mathrm{s}}\right)=-\mathrm{E}_{\mathrm{m}}
$$


$\lim _{t \rightarrow \infty} \mathrm{k}_{\theta} \cdot\left[\theta(\mathrm{t})-\hat{\theta}(\mathrm{t})+\mathrm{E}_{\theta}(\mathrm{t})\right]=\lim _{s \rightarrow 0} \mathrm{~s} \cdot \mathrm{k}_{\theta}^{\mathrm{s}} \cdot\left[\theta^{\mathrm{s}}-\hat{\theta}^{\mathrm{s}}+\mathrm{E}_{\theta}^{\mathrm{s}}\right]=0$.

The angle information converges to zero in the steady state as derived in (11) by virtue of the angle controller. This controller's action may be slightly different when enabling accurate estimations of the rotor angle under any operating conditions. Namely, angle information that is expected to be equal to an angle error is uniformly forced to be zero even if some errors are incorporated into it. Because of this, the G(s) shown in Fig. 2 was represented as an 'angle controller' in this paper rather than an 'angle estimator'.

\section{B. Error Equation in Sensorless Control Systems}

Comparing (10) with (4), the angle errors are definitely caused by additive errors. By discussing the overall sensorless system, it can be seen how additive errors occur. In the rotor $\mathrm{d}-\mathrm{q}$ reference frame, the voltage equation is given as:

$$
\left[\begin{array}{c}
\mathrm{v}_{\mathrm{ds}}^{\mathrm{r}} \\
\mathrm{v}_{\mathrm{qs}}^{\mathrm{r}}
\end{array}\right]=\left[\begin{array}{cc}
\mathrm{R}_{\mathrm{s}}+p \mathrm{~L}_{\mathrm{d}} & -\omega_{\mathrm{r}} \mathrm{L}_{\mathrm{q}} \\
\omega_{\mathrm{r}} \mathrm{L}_{\mathrm{d}} & \mathrm{R}_{\mathrm{s}}+p \mathrm{~L}_{\mathrm{q}}
\end{array}\right]\left[\begin{array}{c}
\mathrm{i}_{\mathrm{ds}}^{\mathrm{r}} \\
\mathrm{i}_{\mathrm{qs}}^{\mathrm{r}}
\end{array}\right]+\left[\begin{array}{c}
0 \\
\omega_{\mathrm{r}} \lambda_{\mathrm{f}}
\end{array}\right]
$$

where $p$ is the derivative operator, and the superscript ' $r$ ' indicates the rotor $d-q$ reference frame. $L_{d}$ and $L_{q}$ are the $d$ - and $\mathrm{q}$-axis synchronous inductances, $\mathrm{R}_{\mathrm{s}}$ is the phase resistance, and $\lambda_{\mathrm{f}}$ is the flux linkage. $\omega_{\mathrm{r}}$ is the rotating speed in the electrical angle.

Considering (1), the voltages in the rotor reference frame can be converted to those in the estimated rotor reference frame:

$$
\left[\begin{array}{c}
\hat{\mathrm{v}}_{\mathrm{ds}}^{\mathrm{r}} \\
\hat{\mathrm{v}}_{\mathrm{qs}}^{\mathrm{r}}
\end{array}\right]=\left[\begin{array}{cc}
\cos \theta_{\mathrm{d}} & -\sin \theta_{\mathrm{d}} \\
\sin \theta_{\mathrm{d}} & \cos \theta_{\mathrm{d}}
\end{array}\right]\left[\begin{array}{c}
\mathrm{v}_{\mathrm{ds}}^{\mathrm{r}} \\
\mathrm{v}_{\mathrm{qs}}^{\mathrm{r}}
\end{array}\right]=\mathrm{T}\left[\theta_{\mathrm{d}}\right]\left[\begin{array}{c}
\mathrm{v}_{\mathrm{ds}}^{\mathrm{r}} \\
\mathrm{v}_{\mathrm{qs}}^{\mathrm{r}}
\end{array}\right] .
$$

Using the matrix $T\left[\theta_{d}\right]$ in (13), the voltage equation in the estimated rotor $\mathrm{d}-\mathrm{q}$ reference frame can be derived as [8]:

$$
\begin{aligned}
& {\left[\begin{array}{c}
\hat{\mathrm{v}}_{\mathrm{ds}}^{\mathrm{r}} \\
\hat{\mathrm{v}}_{\mathrm{qs}}^{\mathrm{r}}
\end{array}\right]=\left[\begin{array}{cc}
\mathrm{R}_{\mathrm{s}}-\omega_{\mathrm{r}} \alpha & -\omega_{\mathrm{r}}\left(\mathrm{L}_{\mathrm{q}}+\beta\right) \\
\omega_{\mathrm{r}}\left(\mathrm{L}_{\mathrm{q}}+\gamma\right) & \mathrm{R}_{\mathrm{s}}+\omega_{\mathrm{r}} \alpha
\end{array}\right]\left[\begin{array}{c}
\hat{\mathrm{i}}_{\mathrm{ds}}^{\mathrm{r}} \\
\hat{\mathrm{i}}_{\mathrm{qs}}^{\mathrm{r}}
\end{array}\right]} \\
& +\left[\begin{array}{cc}
\mathrm{L}_{\mathrm{q}}+\gamma & \alpha \\
\alpha & \mathrm{L}_{\mathrm{q}}+\beta
\end{array}\right]\left[\begin{array}{c}
p \hat{\mathrm{i}}_{\mathrm{ds}}^{\mathrm{r}} \\
p \hat{\mathrm{i}}_{\mathrm{qs}}^{\mathrm{r}}
\end{array}\right]+\omega_{\mathrm{r}} \lambda_{\mathrm{f}}\left[\begin{array}{c}
-\sin \theta_{\mathrm{d}} \\
\cos \theta_{\mathrm{d}}
\end{array}\right] \\
& +\left(\omega_{\mathrm{r}}-\hat{\omega}_{\mathrm{r}}\right) \cdot\left[\begin{array}{cc}
-\alpha & \mathrm{L}_{\mathrm{q}}+\gamma \\
-\left(\mathrm{L}_{\mathrm{q}}+\beta\right) & \alpha
\end{array}\right]\left[\begin{array}{c}
\hat{\mathrm{i}}_{\mathrm{ds}}^{\mathrm{r}} \\
\hat{\mathrm{i}}_{\mathrm{qs}}^{\mathrm{r}}
\end{array}\right]
\end{aligned}
$$

where $\Delta \mathrm{L}=\mathrm{L}_{\mathrm{d}}-\mathrm{L}_{\mathrm{q}}, \quad \alpha=\Delta \mathrm{L} \sin \theta_{\mathrm{d}} \cos \theta_{\mathrm{d}}, \quad \beta=\Delta \mathrm{L} \sin ^{2} \theta_{\mathrm{d}}$, and $\gamma=\Delta \operatorname{L} \cos ^{2} \theta_{d}$.

Since low frequency variations are of great concern according to (6), (14) can be further simplified into (15) considering (8):

$$
\begin{aligned}
& {\left[\begin{array}{c}
\hat{\mathrm{v}}_{\mathrm{ds}}^{\mathrm{r}} \\
\hat{\mathrm{v}}_{\mathrm{qs}}^{\mathrm{r}}
\end{array}\right]=\left[\begin{array}{cc}
\mathrm{R}_{\mathrm{s}}-\omega_{\mathrm{r}} \alpha & -\omega_{\mathrm{r}}\left(\mathrm{L}_{\mathrm{q}}+\beta\right) \\
\omega_{\mathrm{r}}\left(\mathrm{L}_{\mathrm{q}}+\gamma\right) & \mathrm{R}_{\mathrm{s}}+\omega_{\mathrm{r}} \alpha
\end{array}\right]\left[\begin{array}{c}
\hat{\mathrm{i}}_{\mathrm{ds}}^{\mathrm{r}} \\
\hat{\mathrm{i}}_{\mathrm{qs}}^{\mathrm{r}}
\end{array}\right]} \\
& +\left[\begin{array}{cc}
\mathrm{L}_{\mathrm{q}}+\gamma & \alpha \\
\alpha & \mathrm{L}_{\mathrm{q}}+\beta
\end{array}\right]\left[\begin{array}{c}
p \hat{\mathrm{i}}_{\mathrm{ds}}^{\mathrm{r}} \\
p \hat{\mathrm{i}}_{\mathrm{qs}}^{\mathrm{r}}
\end{array}\right]+\omega_{\mathrm{r}} \lambda_{\mathrm{f}}\left[\begin{array}{c}
-\sin \theta_{\mathrm{d}} \\
\cos \theta_{\mathrm{d}}
\end{array}\right]
\end{aligned}
$$

The ' $\sin \theta_{\mathrm{d}}$ ' in (15) can be used as angle information because it is proportional to the angle error. However, how to extract this component can be different with each of the sensorless

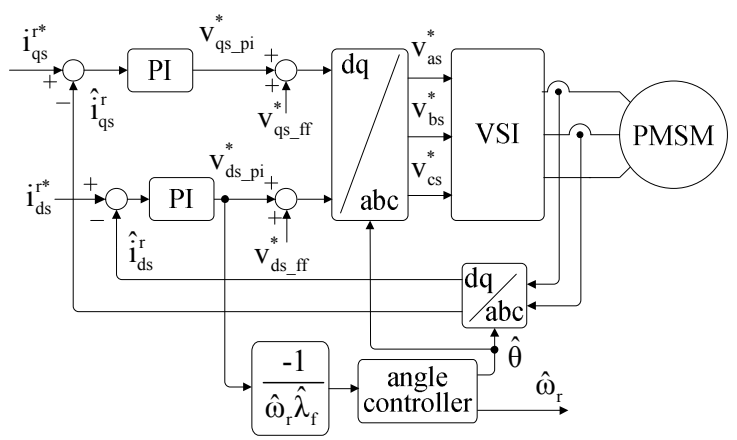

Fig. 3. A sensorless control method

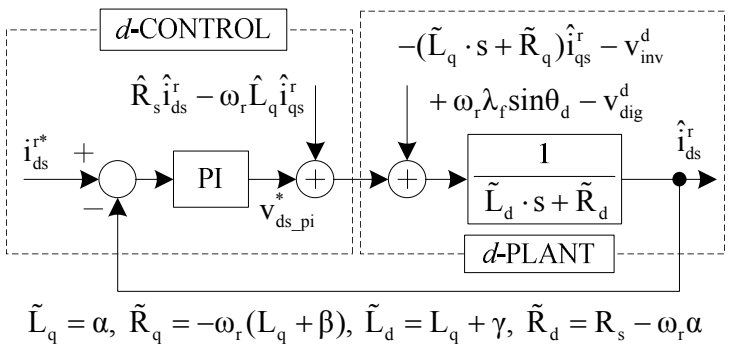

Fig. 4. Control loop for d-axis current.

control methods in [1]-[4]. In the sensorless control method of interest, it is assumed that ' $\sin \theta_{\mathrm{d}}$ ' can be obtained from the d-axis PI output through scaling, as shown in Fig. 3 [1], [5], where the feed-forward terms are given as:

$$
\left[\begin{array}{c}
v_{\mathrm{ds}_{-} \mathrm{ff}} \\
\mathrm{v}_{\mathrm{q} \mathrm{f}_{-} \mathrm{ff}}
\end{array}\right]=\left[\begin{array}{c}
\hat{\mathrm{R}}_{\mathrm{s}} \hat{\mathrm{i}}_{\mathrm{ds}}^{\mathrm{r}}-\hat{\omega}_{\mathrm{r}} \hat{\mathrm{L}}_{\mathrm{q}} \hat{\mathrm{i}}_{\mathrm{qs}}^{\mathrm{r}} \\
\hat{\mathrm{R}} \hat{\mathrm{i}}_{\mathrm{qs}}^{\mathrm{r}}+\hat{\omega}_{\mathrm{r}} \hat{\mathrm{L}}_{\mathrm{d}} \hat{\mathrm{i}}_{\mathrm{ds}}^{\mathrm{r}}+\hat{\omega}_{\mathrm{r}} \hat{\lambda}_{\mathrm{f}}
\end{array}\right] .
$$

However, modeling based on (15) may be insufficient to accurately extract ' $\sin \theta_{\mathrm{d}}$ ' since the driving system for the PMSM is not reflected. Namely, the actual output voltages are assumed to be identical to their references. When the distortions between the actual outputs and their references are considered, the voltage equation can be modified as:

$$
\begin{array}{r}
{\left[\begin{array}{c}
\hat{\mathrm{v}}_{\mathrm{ds}}^{\mathrm{r}^{*}} \\
\hat{\mathrm{v}}_{\mathrm{qs}}^{\mathrm{r}^{*}}
\end{array}\right]=\left[\begin{array}{cc}
\mathrm{R}_{\mathrm{s}}-\omega_{\mathrm{r}} \alpha & -\omega_{\mathrm{r}}\left(\mathrm{L}_{\mathrm{q}}+\beta\right) \\
\omega_{\mathrm{r}}\left(\mathrm{L}_{\mathrm{q}}+\gamma\right) & \mathrm{R}_{\mathrm{s}}+\omega_{\mathrm{r}} \alpha
\end{array}\right]\left[\begin{array}{c}
\hat{\mathrm{i}}_{\mathrm{ds}}^{\mathrm{r}} \\
\hat{\mathrm{i}}_{\mathrm{qs}}^{\mathrm{r}}
\end{array}\right]+\left[\begin{array}{c}
\mathrm{v}_{\mathrm{inv}}^{\mathrm{d}} \\
\mathrm{v}_{\mathrm{inv}}^{\mathrm{q}}
\end{array}\right]+\left[\begin{array}{c}
\mathrm{v}_{\mathrm{dig}}^{\mathrm{d}} \\
\mathrm{v}_{\mathrm{dig}}^{\mathrm{q}}
\end{array}\right]} \\
+\left[\begin{array}{cc}
\mathrm{L}_{\mathrm{q}}+\gamma & \alpha \\
\alpha & \mathrm{L}_{\mathrm{q}}+\beta
\end{array}\right]\left[\begin{array}{c}
p \hat{\mathrm{i}}_{\mathrm{ds}}^{\mathrm{r}} \\
p \hat{\mathrm{i}}_{\mathrm{qs}}^{\mathrm{r}}
\end{array}\right]+\omega_{\mathrm{r}} \lambda_{\mathrm{f}}\left[\begin{array}{c}
-\sin \theta_{\mathrm{d}} \\
\cos \theta_{\mathrm{d}}
\end{array}\right]
\end{array}
$$

where the subscript 'inv' represents the distorted voltages due to inverter nonlinearity and the subscript 'dig' represents those due to digital delay. The superscript ' $*$ ' represents a reference variable.

Based on (17), the current control loops can be described. In particular, the d-axis control loop is detailed since only that axis is related to angle estimation, as shown in Fig. 3. The d-axis control loop was depicted in Fig. 4 considering (17). From the figure, the Laplace transfer function for the d-axis PI output can be derived as: 


$$
\begin{aligned}
& \mathrm{v}_{\mathrm{ds}, \mathrm{pi}}^{*}=\frac{\mathrm{k}_{\mathrm{pd}} \tilde{\mathrm{L}}_{\mathrm{d}} \mathrm{s}^{2}+\left(\mathrm{k}_{\mathrm{id}} \tilde{\mathrm{L}}_{\mathrm{d}}+\mathrm{k}_{\mathrm{pd}} \tilde{\mathrm{R}}_{\mathrm{d}}\right) \mathrm{s}+\mathrm{k}_{\mathrm{id}} \tilde{\mathrm{R}}_{\mathrm{d}}}{\tilde{\mathrm{L}}_{\mathrm{d}} \mathrm{s}^{2}+\left(\mathrm{k}_{\mathrm{pd}}+\tilde{\mathrm{R}}_{\mathrm{d}}\right) \mathrm{s}+\mathrm{k}_{\mathrm{id}}} \\
& \quad-\frac{\mathrm{k}_{\mathrm{pd}} \mathrm{s}+\mathrm{k}_{\mathrm{id}}}{\tilde{\mathrm{L}}_{\mathrm{d}} \mathrm{s}^{2}+\left(\mathrm{k}_{\mathrm{pd}}+\tilde{\mathrm{R}}_{\mathrm{d}}\right) \mathrm{s}+\mathrm{k}_{\mathrm{id}}} \\
& \times\left\{\hat{\mathrm{R}}_{\mathrm{s}} \hat{\mathrm{i}}_{\mathrm{ds}}^{\mathrm{r}}-\omega_{\mathrm{r}} \hat{\mathrm{L}}_{\mathrm{q}} \hat{\mathrm{i}}_{\mathrm{qs}}^{\mathrm{r}}-\left(\tilde{\mathrm{L}}_{\mathrm{q}} \mathrm{s}+\tilde{\mathrm{R}}_{\mathrm{q}}\right) \hat{\mathrm{i}}_{\mathrm{qs}}^{\mathrm{r}}+\omega_{\mathrm{r}} \lambda_{\mathrm{f}} \sin \theta_{\mathrm{d}}-\mathrm{v}_{\mathrm{inv}}^{\mathrm{d}}-\mathrm{v}_{\mathrm{dig}}^{\mathrm{d}}\right\}
\end{aligned}
$$

where $\mathrm{k}_{\mathrm{pd}}$ and $\mathrm{k}_{\mathrm{id}}$ are the PI gains for the $\mathrm{d}$-axis control.

The following approximations are acceptable since $\theta_{\mathrm{d}}$ and $\mathrm{L}_{\mathrm{d}}-\mathrm{L}_{\mathrm{q}}$ are relatively small:

$$
\begin{gathered}
\sin \theta_{\mathrm{d}} \approx \theta_{\mathrm{d}}, \cos \theta_{\mathrm{d}} \approx 1 \\
\left\{\begin{array}{l}
\mathrm{L}_{\mathrm{q}} \gg \beta \approx\left(\mathrm{L}_{\mathrm{d}}-\mathrm{L}_{\mathrm{q}}\right) \cdot \theta_{\mathrm{d}}^{2} \\
\mathrm{R}_{\mathrm{s}} \gg \omega_{\mathrm{r}} \alpha \approx \omega_{\mathrm{r}} \cdot\left(\mathrm{L}_{\mathrm{d}}-\mathrm{L}_{\mathrm{q}}\right) \cdot \theta_{\mathrm{d}}
\end{array} .\right.
\end{gathered}
$$

If the currents, angle error and distorted voltages in (18) can be modeled as the step signals in (21), the d-axis PI output in the steady state can be derived as (22) at the rotating speed:

$$
\begin{aligned}
& \qquad \begin{array}{l}
\mathrm{i}_{\mathrm{ds}}^{\mathrm{r}^{*}}=\hat{\mathrm{i}}_{\mathrm{ds}}^{\mathrm{r}}=\mathrm{I}_{\mathrm{d}} / \mathrm{s}, \hat{\mathrm{i}}_{\mathrm{qs}}^{\mathrm{r}}=\mathrm{I}_{\mathrm{q}} / \mathrm{s} \\
\theta_{\mathrm{d}}=\Theta_{\mathrm{d}} / \mathrm{s} \\
\mathrm{v}_{\text {inv }}^{\mathrm{d}}=\mathrm{V}_{\text {inv }} / \mathrm{s}, \mathrm{v}_{\mathrm{dig}}^{\mathrm{d}}=\mathrm{V}_{\mathrm{dig}} / \mathrm{s}
\end{array} \\
& \lim _{t \rightarrow \infty} \mathrm{v}_{\mathrm{ds} \_\mathrm{pi}}^{*}=\lim _{s \rightarrow 0} \mathrm{~s} \cdot \mathrm{v}_{\mathrm{ds} \mathrm{pi}}^{*} \\
& \approx\left(\mathrm{R}_{\mathrm{s}}-\hat{\mathrm{R}}_{\mathrm{s}}\right) \cdot \mathrm{I}_{\mathrm{d}}+\omega_{\mathrm{r}}\left(\hat{\mathrm{L}}_{\mathrm{q}}-\mathrm{L}_{\mathrm{q}}\right) \cdot \mathrm{I}_{\mathrm{q}}-\omega_{\mathrm{r}} \lambda_{\mathrm{f}} \Theta_{\mathrm{d}}+\mathrm{V}_{\text {inv }}+\mathrm{V}_{\text {dig }}
\end{aligned}
$$

Because the d-axis PI output, $\mathrm{v}_{\mathrm{ds} \text { pi }}^{*}$, is used as the input to the angle controller in Fig. 2, it converges to zero in the steady state according to (11). That is, the left side of (22) tends to zero. Then, (22) can be rewritten as:

$$
\Theta_{\mathrm{d}} \approx \frac{1}{\lambda_{\mathrm{f}}}\left\{\left(\hat{\mathrm{L}}_{\mathrm{q}}-\mathrm{L}_{\mathrm{q}}\right) \cdot \mathrm{I}_{\mathrm{q}}-\frac{\left(\hat{\mathrm{R}}_{\mathrm{s}}-\mathrm{R}_{\mathrm{s}}\right)}{\omega_{\mathrm{r}}} \cdot \mathrm{I}_{\mathrm{d}}+\frac{\mathrm{V}_{\mathrm{inv}}}{\omega_{\mathrm{r}}}+\frac{\mathrm{V}_{\mathrm{dig}}}{\omega_{\mathrm{r}}}\right\} .
$$

In (23), the error causing factors are evident. Among the parameters of a PMSM, the q-axis inductance and the stator winding resistance used for control contribute to angle errors. Although the distorted voltages by the driving platform can also affect angle errors, their effect should be further described.

\section{Distorted Voltages Due to the Inverter Nonlinearity}

The nonlinearity of an inverter originates from the practical properties of the inverter [9]-[12]. This nonlinearity per phase changes depending on the sign of the output current. Because the output currents are regulated as sine-waves, the distortions due to nonlinearity are also periodic. This means that the distorted voltage due to the inverter can be expressed with a Fourier series, comprised of harmonic voltages. Among the harmonics, the fundamental one is dominant in magnitude [12].

Since the fundamental of the distorted voltages are in phase with the fundamental currents, the $\mathrm{d}$-q ratios of the voltage and the current vectors are identical to each other. This can be expressed as:

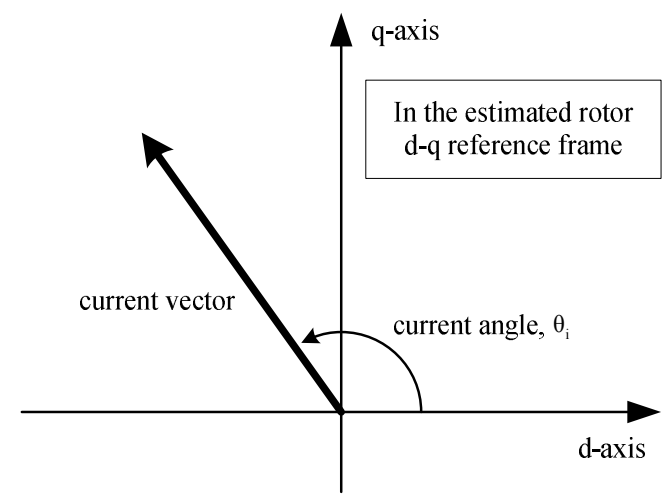

Fig. 5. Definition of current angle $\theta_{\mathrm{i}}$.

$$
\left\{\begin{array}{l}
\mathrm{v}_{\mathrm{inv1}}^{\mathrm{d}}=\frac{\hat{\mathrm{i}}_{\mathrm{dsl}}^{\mathrm{r}}}{\sqrt{\left(\hat{\mathrm{i}}_{\mathrm{ds} 1}^{\mathrm{r}}\right)^{2}+\left(\hat{\mathrm{i}}_{\mathrm{qsl}}^{\mathrm{r}}\right)^{2}}} \cdot \sqrt{\left(\mathrm{v}_{\mathrm{inv1}}^{\mathrm{d}}\right)^{2}+\left(\mathrm{v}_{\mathrm{inv1}}^{\mathrm{q}}\right)^{2}} \\
\mathrm{v}_{\mathrm{inv1}}^{\mathrm{q}}=\frac{\hat{\mathrm{i}}_{\mathrm{qs} 1}^{\mathrm{r}}}{\sqrt{\left(\hat{\mathrm{i}}_{\mathrm{ds} 1}^{\mathrm{r}}\right)^{2}+\left(\hat{\mathrm{i}}_{\mathrm{qsl}}^{\mathrm{r}}\right)^{2}}} \cdot \sqrt{\left(\mathrm{v}_{\mathrm{inv1}}^{\mathrm{d}}\right)^{2}+\left(\mathrm{v}_{\mathrm{inv1}}^{\mathrm{q}}\right)^{2}}
\end{array}\right.
$$

where the subscript ' 1 ' represents the fundamental.

The distorted voltages in (24) can be further simplified into (25) with the definitions of (26) and Fig. 5:

$$
\begin{aligned}
& \left\{\begin{array}{c}
\mathrm{v}_{\text {inv }}^{\mathrm{d}}=\cos \theta_{\mathrm{i}} \cdot \mathrm{M}_{\mathrm{inv1}} \\
\mathrm{v}_{\mathrm{inv}}^{\mathrm{q}}=\sin \theta_{\mathrm{i}} \cdot \mathrm{M}_{\mathrm{invl}}
\end{array}\right. \\
& \mathrm{M}_{\text {invl }}=\sqrt{\left(\mathrm{v}_{\text {inv1 }}^{\mathrm{d}}\right)^{2}+\left(\mathrm{v}_{\text {inv1 }}^{\mathrm{q}}\right)^{2}} .
\end{aligned}
$$

The d-axis voltage in (25) can be substituted with $\mathrm{V}_{\text {inv }}$ in (23) considering (21).

\section{Distorted Voltages Due to Digital Delay}

Recently, most motor drive systems are implemented with digital controls by means of a Digital Signal Processor (DSP). Since the source codes of a DSP are only executed per finite times, Pulse Width Modulation (PWM) is used to averagely synthesize voltage outputs during a period. Moreover, because a certain time is consumed in computing the voltage references for the PWM, these references in the present period should be synthesized during the next period.

However, during the delay time, the rotor of a PMSM rotates at a speed. That is, the voltage vectors synthesized by PWM may be applied in unintended directions. If these rotating errors are not negligible, the driving performance can be limited and the system may fall into instability. To solve these problems, a simple compensation method was suggested in [13].

The compensation method in [13] can be understood with Fig. 6. The original voltage references were assumed to be:

$$
\left\{\begin{array}{l}
\mathrm{v}_{\mathrm{d} \_ \text {origin }}^{\mathrm{r}^{*}}=0 \\
\mathrm{v}_{\mathrm{q} \text { _origin }}^{\mathrm{r}^{*}}=\alpha(\alpha \neq 0)
\end{array} .\right.
$$

The original references and the actual outputs were displayed in the rotor $\mathrm{d}-\mathrm{q}$ reference frame in Fig. 6. In the 

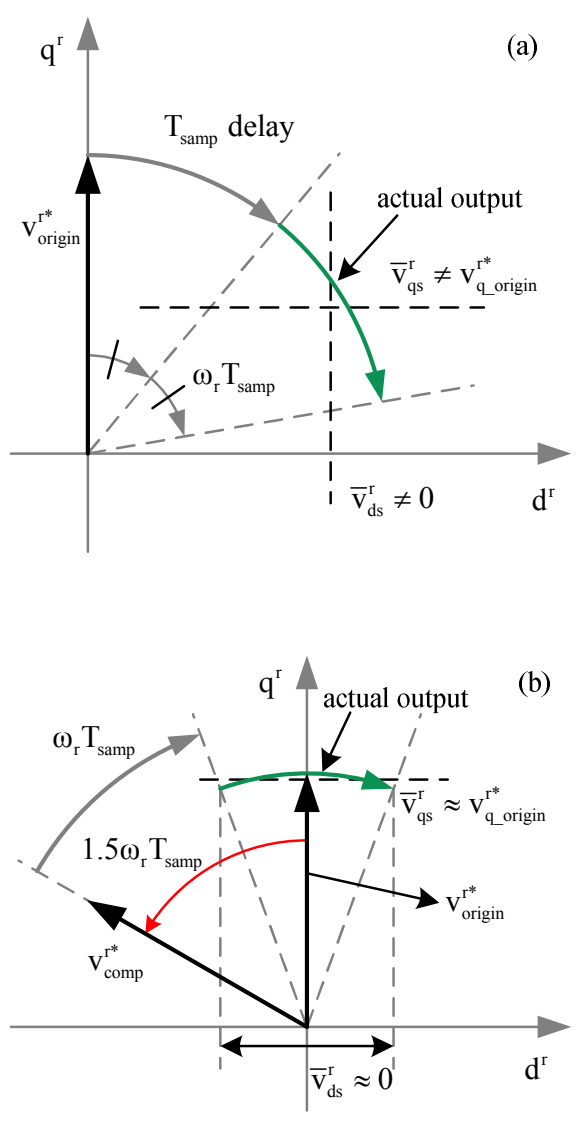

Fig. 6. Compensation for the digital delay : (a) no compensation, (b) with compensation.

figure, the bar '-' over a variable represents the average of that variable and $\mathrm{T}_{\text {samp }}$ is one sampling period. As shown in Fig. 6(a), if there is no compensation, the averages of the actual d-q voltages deviate from the original references. Only the average distortions were considered for analysis since those are dominant in low frequency variations. To compensate for the digital delay, the voltage references can be intentionally rotated ahead by $1.5 \omega_{\mathrm{r}} \mathrm{T}_{\text {samp, }}$ as shown in Fig. 6(b) [13]. Then, the averages of the actual voltage output can become almost equal to the original references.

Considering the compensation principle, the required voltage references can be approximately expressed as:

$$
\left[\begin{array}{c}
\mathrm{v}_{\mathrm{ds}}^{\mathrm{r}^{*}} \\
\mathrm{v}_{\mathrm{qs}}^{\mathrm{r}^{*}}
\end{array}\right] \approx\left[\begin{array}{cc}
\cos \left(1.5 \omega_{\mathrm{r}} \mathrm{T}_{\text {samp }}\right) & -\sin \left(1.5 \omega_{\mathrm{r}} \mathrm{T}_{\text {samp }}\right) \\
\sin \left(1.5 \omega_{\mathrm{r}} \mathrm{T}_{\text {samp }}\right) & \cos \left(1.5 \omega_{\mathrm{r}} \mathrm{T}_{\text {samp }}\right)
\end{array}\right]\left[\begin{array}{c}
\mathrm{v}_{\mathrm{ds}}^{\mathrm{r}} \\
\mathrm{v}_{\mathrm{qs}}^{\mathrm{r}}
\end{array}\right] \text {. }
$$

In a practical system using feedback controllers, the voltage references are changed in real time to appropriately regulate the output currents. Namely, if there is no compensation, the integrators of the controllers work for balancing the voltage distortions caused by the digital delay. Considering (28), the balancing voltages accumulated in the integrators can be approximated as:

$$
\begin{aligned}
& {\left[\begin{array}{c}
\mathrm{v}_{\mathrm{dig}}^{\mathrm{d}} \\
\mathrm{v}_{\mathrm{dig}}^{\mathrm{q}}
\end{array}\right]=\left[\begin{array}{c}
\mathrm{v}_{\mathrm{ds}}^{\mathrm{r}^{*}}-\mathrm{v}_{\mathrm{ds}}^{\mathrm{r}} \\
\mathrm{v}_{\mathrm{qs}}^{\mathrm{r}^{*}}-\mathrm{v}_{\mathrm{qs}}^{\mathrm{r}}
\end{array}\right]} \\
& =\left[\begin{array}{cc}
1-\cos \left(1.5 \omega_{\mathrm{r}} \mathrm{T}_{\mathrm{samp}}\right) & -\sin \left(1.5 \omega_{\mathrm{r}} \mathrm{T}_{\text {samp }}\right) \\
\sin \left(1.5 \omega_{\mathrm{r}} \mathrm{T}_{\text {samp }}\right) & 1-\cos \left(1.5 \omega_{\mathrm{r}} \mathrm{T}_{\text {samp }}\right)
\end{array}\right]\left[\begin{array}{c}
\mathrm{v}_{\mathrm{ds}}^{\mathrm{r}^{*}} \\
\mathrm{v}_{\mathrm{qs}}^{\mathrm{r}^{*}}
\end{array}\right]^{.}
\end{aligned}
$$

More approximations similar to (19) can be applied to (29) since the value of $1.5 \omega_{\mathrm{r}} \mathrm{T}_{\text {samp }}$ is small enough. Then, (29) is simplified into (30). If (21) is considered, the d-axis voltage in (30) can be substituted with $\mathrm{V}_{\text {dig }}$ in (23).

$$
\left[\begin{array}{c}
\mathrm{v}_{\mathrm{dig}}^{\mathrm{d}} \\
\mathrm{v}_{\mathrm{dig}}^{\mathrm{q}}
\end{array}\right] \approx\left[\begin{array}{cc}
0 & -1.5 \omega_{\mathrm{r}} \mathrm{T}_{\mathrm{samp}} \\
1.5 \omega_{\mathrm{r}} \mathrm{T}_{\text {samp }} & 0
\end{array}\right]\left[\begin{array}{c}
\mathrm{v}_{\mathrm{ds}}^{\mathrm{r}^{*}} \\
\mathrm{v}_{\mathrm{qs}}^{\mathrm{r}^{*}}
\end{array}\right] \text {. }
$$

\section{E. Detailed Error Equation}

From (21), (23), (25), (26) and (30), the error equation can be derived as:

$$
\begin{aligned}
\theta_{\mathrm{d}} \approx \frac{1}{\lambda_{\mathrm{f}}}\left\{\left(\hat{\mathrm{L}}_{\mathrm{q}}-\mathrm{L}_{\mathrm{q}}\right) \cdot \hat{\mathrm{i}}_{\mathrm{qs}}^{\mathrm{r}}-\frac{\left(\hat{\mathrm{R}}_{\mathrm{s}}-\mathrm{R}_{\mathrm{s}}\right)}{\omega_{\mathrm{r}}} \cdot \hat{\mathrm{i}}_{\mathrm{ds}}^{\mathrm{r}}\right. \\
\left.+\frac{\mathrm{M}_{\text {invl }} \cos \theta_{\mathrm{i}}}{\omega_{\mathrm{r}}}-1.5 \mathrm{~T}_{\text {samp }} \cdot \hat{\mathrm{V}}_{\mathrm{qs}}^{\mathrm{r}^{*}}\right\}
\end{aligned} .
$$

It can be clearly understood through (31) which factors result in angle errors. Compared with [5], the effects of the driving system were additionally detailed in the error equation. It is also easy to figure out the conditions under which the angle error from a specific factor increases or decreases. Each term in (31) is scrutinized with experimental results.

\section{SIMULATIONS AND EXPERIMENTS}

\section{A. Experimental Set- $U p$}

An 8-pole Surface Mounted PMSM (SMPMSM) was used to observe angle errors. Its rated speed is $1500 \mathrm{r} / \mathrm{min}$ and its rated current is $15 \mathrm{~A}_{\mathrm{rms}}$. In addition, an induction machine was used to apply a load torque to the SMPMSM. Although a 5000 ppr encoder was installed, as shown in Fig. 7, this encoder was only used to measure angle errors in real time. Namely, the SMPMSM was driven by the sensorless control method in [1].

The dc-link voltage of the VSIs for the motors was about $310 \mathrm{~V}$. The controllers were implemented on a DSP board based on a TMS320VC33, whose sampling period was set at $100 \mu \mathrm{s}$. In addition, the switching period was $200 \mu$ s and the dead-time was set at $3 \mu$ s.

To consider the effect of the flux linkage of the permanent magnet in the error equation, the interior PMSMs (IPMSM) shown in Fig. 8 were also considered, whose rotors and stators can be interchanged.

\section{B. Simulation and Experimental Results}

In the following results, the angle errors were displayed with the relevant variables composing each term in (31). The tendency of the error equation can be confirmed by changing the relevant variables. 


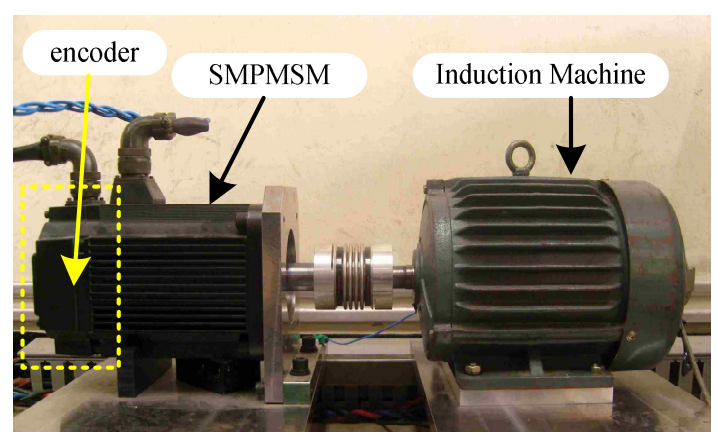

Fig. 7. Experimental set-up for the SMPMSM.

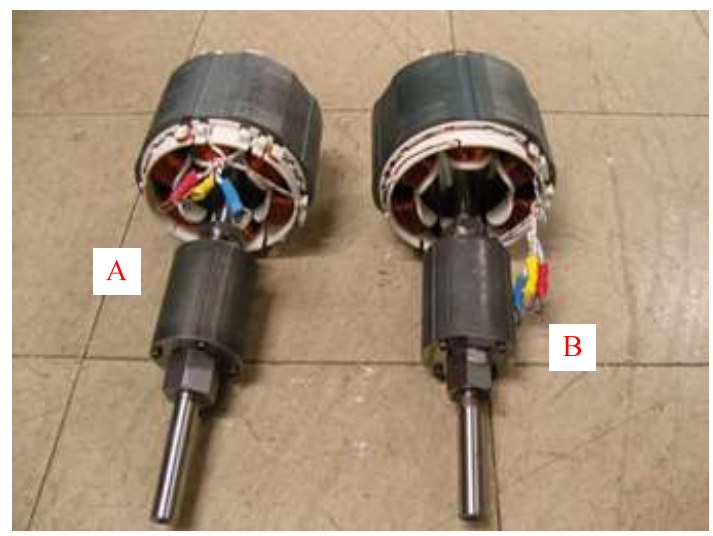

Fig. 8. IPMSMs used for experiments.

First, by setting the motor currents to null at a certain rotating speed, (31) can be simplified into:

$$
\theta_{\mathrm{d}} \approx \frac{1}{\lambda_{\mathrm{f}}}\left(-1.5 \mathrm{~T}_{\mathrm{samp}} \cdot \hat{\mathrm{v}}_{\mathrm{qs}}^{\mathrm{r*}}\right) \text {. }
$$

In general, the d-axis current is regulated to null for a SMPMSM. To fulfill the conditions required for (32), the load torque by the induction machine was adjusted toward canceling out the friction torque. As a result, the q-axis current that contributes to the torque was also maintained at around zero, as shown in Fig. 9(a). Although the all of the currents are almost zero, the q-axis voltage reference can still be varied by the back EMFs. Then, the mechanical speed was increased from 400 r/min to $1200 \mathrm{r} / \mathrm{min}$ by $200 \mathrm{r} / \mathrm{min}$ increments. In Fig. 9(a), as the speed increased, the q-axis voltage references increased and the magnitude of the angle error also increased. These variations correspond to the predictions based on (32).

The same procedure was repeated while the digital delay was compensated by the method in [13]. As a result, the angle errors were maintained at around zero, as shown in Fig. 9(b) despite the same speed variations. That is, the angle errors in Fig. 9(a) are regarded as being caused by the digital delay and are evidently mitigated by the compensation. Although (32) was not very accurate in terms of figures, the mechanism that reflects the digital delay on the angle errors could be well explained with the error equation. In the all of the following results, the compensation for the digital delay is fundamentally
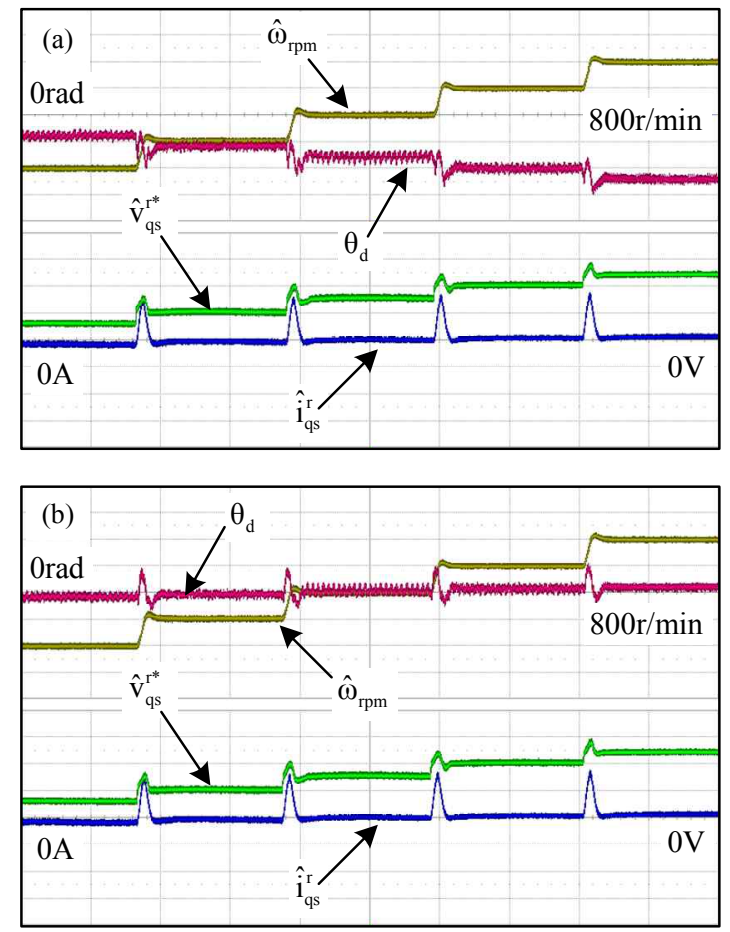

Fig. 9. Angle errors by the digital control with $-1 \mathrm{~N}-\mathrm{m}$ load, (a) without compensation, (b) with compensation : $\theta_{\mathrm{d}} \quad[0.05 \mathrm{rad} / \mathrm{div}]$, $\hat{\omega}_{\mathrm{rpm}}[200 \mathrm{r} / \mathrm{min} / \mathrm{div}], \hat{\mathrm{i}}_{\mathrm{qs}}^{\mathrm{r}}[2 \mathrm{~A} / \mathrm{div}], \hat{\mathrm{v}}_{\mathrm{qs}}^{\mathrm{r}}[20 \mathrm{~V} / \mathrm{div}]$, Time [2s/div].

assumed.

When the d-axis current is regulated to be zero and the q-axis current is not, the current angle can be $\pi / 2$ or $-\pi / 2$ according to Fig. 5. This means that the cosine of the current angle is zero. Then, error equation (31) can be simplified into:

$$
\theta_{\mathrm{d}} \approx \frac{1}{\lambda_{\mathrm{f}}} \cdot\left(\hat{\mathrm{L}}_{\mathrm{s}}-\mathrm{L}_{\mathrm{s}}\right) \cdot \hat{\mathrm{i}}_{\mathrm{qs}}^{\mathrm{r}}
$$

where $\mathrm{L}_{\mathrm{s}}$ is the synchronous inductance of the SMPMSM since the $\mathrm{d}$-q inductances are identical in SMPMSMs.

The accuracy of (33) can be confirmed in the simulation result of Fig. 10(a), where the inverter is ideal. Namely, the angle errors are accurately predicted by (33) even in terms of the figures when the actual $\mathrm{L}_{\mathrm{s}}$ was set to $2.6 \mathrm{mH}$ in the simulation. Considering the small differences between the q-axis currents, the angle errors in the experiment shown in Fig. 10(b) presents almost the same results.

In Fig. 11, only the load torque was increased from $3 \mathrm{~N}-\mathrm{m}$ to $7 \mathrm{~N}-\mathrm{m}$ when compared with Fig. 10(b). Because the average q-axis current increased up to $12.8 \mathrm{~A}$, the angle error per inductance error increased as predicted by (33).

The terms in (31), which have not been discussed yet, are all related to the d-axis current. This means that the effects of each term must be superimposed when the d-axis current is not zero. However, each variation could be distinguished in the test set-up because they were very different in magnitude. 

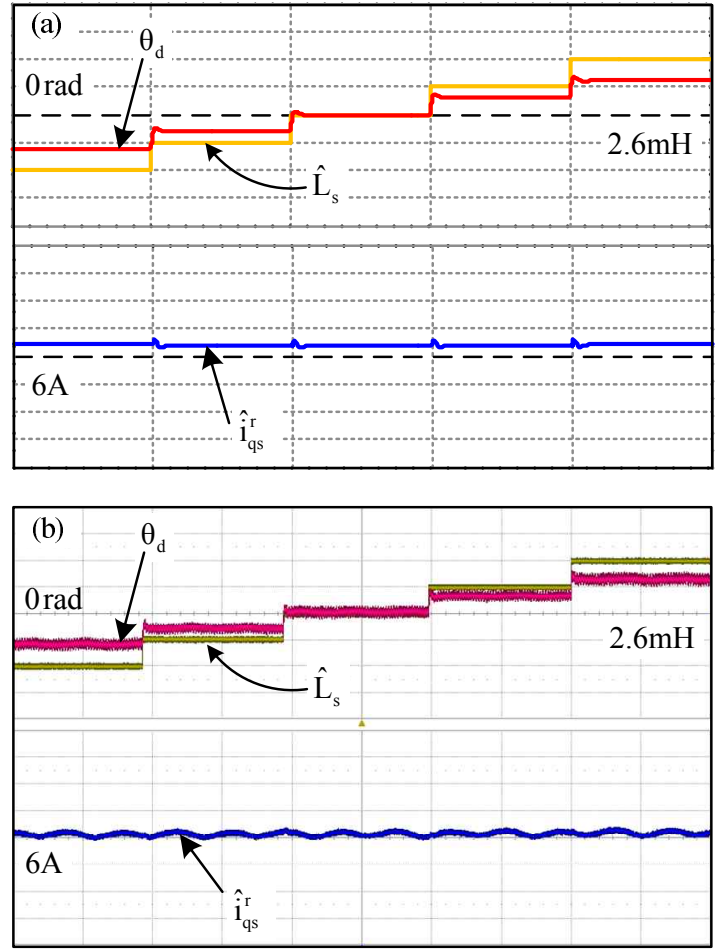

Fig. 10. Angle errors by inductance errors with $3 \mathrm{~N}-\mathrm{m}$ load at 800r/min, (a) simulation, (b) experiment : $\theta_{\mathrm{d}} \quad[0.05 \mathrm{rad} / \mathrm{div}]$, $\hat{\mathrm{L}}_{\mathrm{s}}[0.5 \mathrm{mH} / \mathrm{div}], \quad \hat{\mathrm{i}}_{\mathrm{qs}}^{\mathrm{r}}[0.5 \mathrm{~A} / \mathrm{div}]$, Time [2s/div].

First, the term from the inverter nonlinearity was considered when a stator resistance accepted as being accurate was used for control. If the inductance and resistance for the control are accurate, (31) can be simplified into:

$$
\theta_{\mathrm{d}} \approx \frac{1}{\lambda_{\mathrm{f}}} \cdot \frac{\mathrm{M}_{\mathrm{inv1}} \cos \theta_{\mathrm{i}}}{\omega_{\mathrm{r}}}
$$

To observe the tendency in (34), the d-axis current was adjusted under no load, as shown in Fig. 12(a). As a result, the angle errors presented a cosine pattern as predicted by (34). In addition, the influence of the rotating speed in (34) can be confirmed through a comparison of Figs. 12(a) and (b). Because the speed was doubled in Fig. 12(b), the angle errors were reduced to half of those in Fig. 12(a) while the cosine-variations of current angles were almost the same.

Now, the remaining term is related to the resistance error. When the inverter nonlinearity is compensated [12] and the inductance for the control is accurate, (31) can be simplified into:

$$
\theta_{\mathrm{d}} \approx \frac{1}{\lambda_{\mathrm{f}}} \cdot-\frac{\left(\hat{\mathrm{R}}_{\mathrm{s}}-\mathrm{R}_{\mathrm{s}}\right)}{\omega_{\mathrm{r}}} \cdot \hat{\mathrm{i}}_{\mathrm{ds}}^{\mathrm{r}} .
$$

According to (35), when the d-axis current is negative, the angle errors are proportional to the resistance errors. This tendency was examined through the simulation, where the inverter is ideal and the actual resistance was set to $0.224 \Omega$.

The expected proportionality was confirmed in Fig. 13(a).

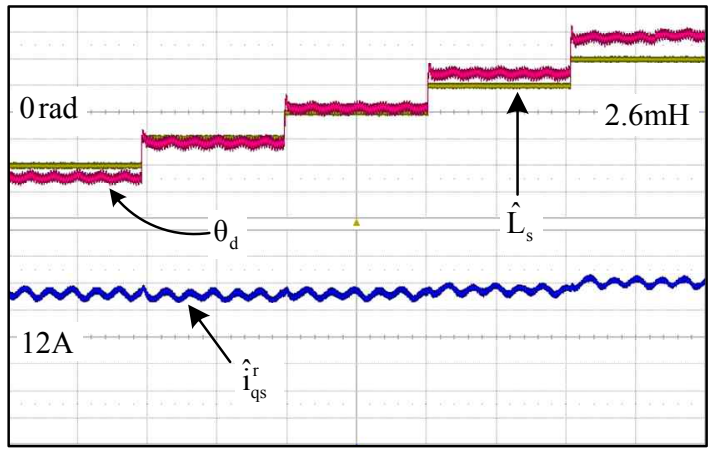

Fig. 11. Angle errors by inductance errors with $7 \mathrm{~N}-\mathrm{m}$ at $800 \mathrm{r} / \mathrm{min}$ : $\theta_{\mathrm{d}}[0.05 \mathrm{rad} / \mathrm{div}], \quad \hat{\mathrm{L}}_{\mathrm{s}}[0.5 \mathrm{mH} / \mathrm{div}], \quad \hat{\mathrm{i}}_{\mathrm{qs}}^{\mathrm{r}}[0.5 \mathrm{~A} / \mathrm{div}]$, Time [2s/div].
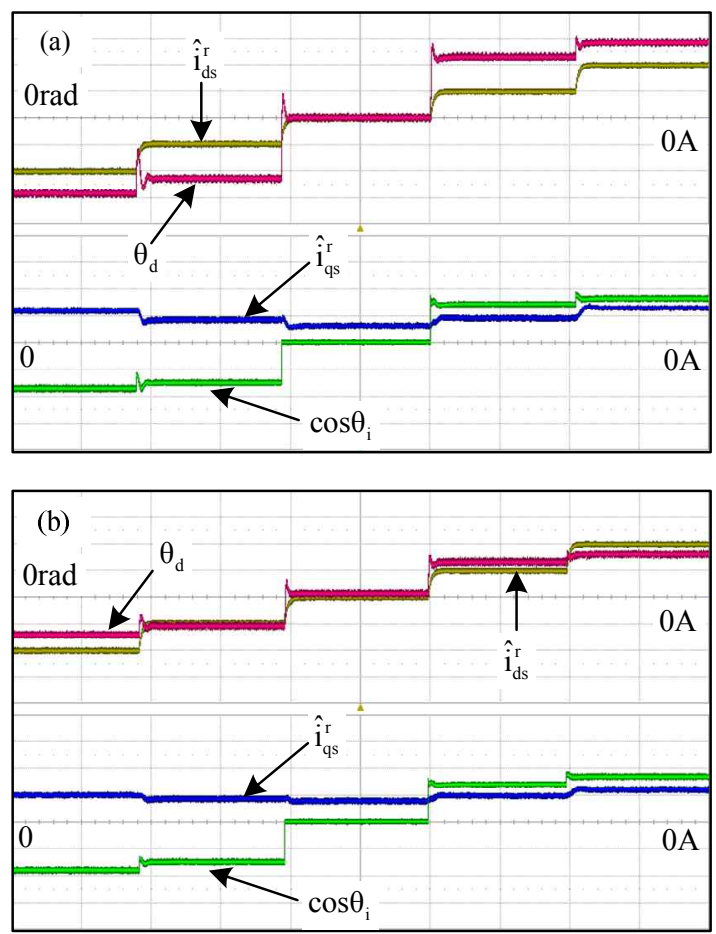

Fig. 12. Angle error by the inverter nonlinearity with no load, (a) $500 \mathrm{r} / \mathrm{min}, \quad$ (b) $1000 \mathrm{r} / \mathrm{min}: \theta_{\mathrm{d}} \quad[0.1 \mathrm{rad} / \mathrm{div}], \quad \hat{\mathrm{i}}_{\mathrm{ds}}^{\mathrm{r}} \quad[2 \mathrm{~A} / \mathrm{div}]$, $\hat{\mathrm{i}}_{\mathrm{qs}}^{\mathrm{r}}[2 \mathrm{~A} / \mathrm{div}], \quad \cos \theta_{\mathrm{i}}[0.5 / \mathrm{div}], \quad$ Time $[2 \mathrm{~s} / \mathrm{div}]$.

Furthermore, the observed angle errors coincided with the calculated errors by (35) and very similar waveforms were observed in the experiment of Fig. 13(b). This correspondence means that (35) is valid, and that the angle errors in Fig. 12 originated from the inverter nonlinearity because the compensated result was equal to the ideal results. Additionally, to consider the effect of speed in (35), the speed was doubled in Fig. 14. As expected by (35), the angle error per the resistance error was reduced by the speed increment.

Although each term in (31) has been discussed, the multiplicative effect of the flux linkage has not been considered. For this consideration, the IPMSMs in Fig. 8 were used. The rotor of one IPMSM was demagnetized through over currents. That is, the flux density of one of the rotor's magnets was 

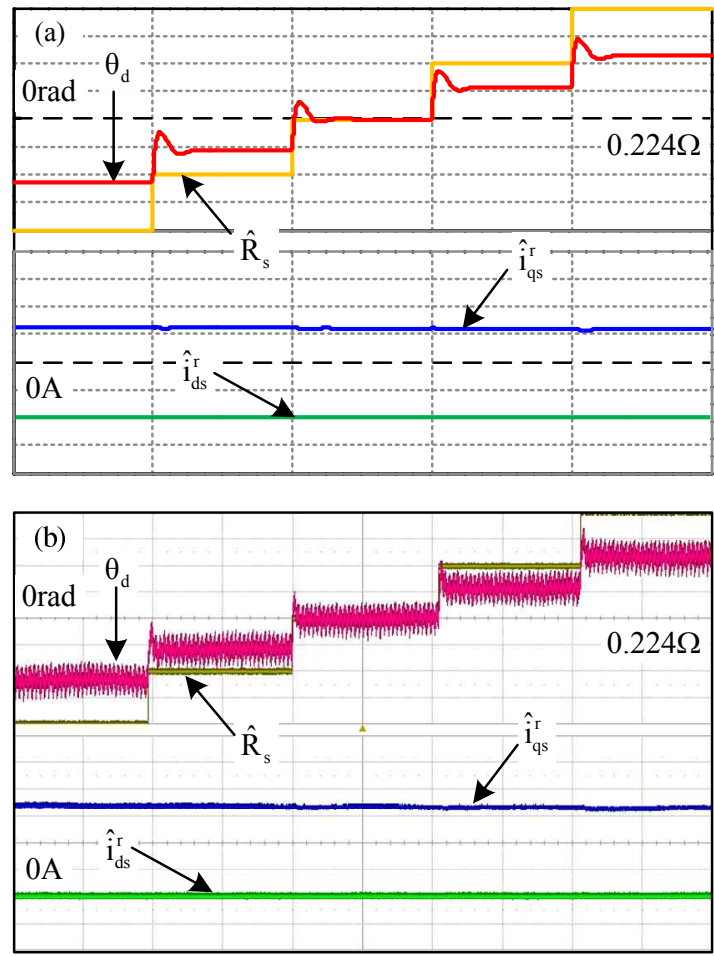

Fig. 13. Angle error by resistance errors with $1 \mathrm{~N}-\mathrm{m}$ load at 500r/min, (a) simulation, (b) experiment : $\theta_{\mathrm{d}}[0.01 \mathrm{rad} / \mathrm{div}]$, $\hat{\mathrm{R}}_{\mathrm{s}}[0.03 \Omega / \mathrm{div}], \hat{\mathrm{i}}_{\mathrm{ds}}^{\mathrm{r}}[2 \mathrm{~A} / \mathrm{div}], \hat{\mathrm{i}}_{\mathrm{qs}}^{\mathrm{r}}[2 \mathrm{~A} / \mathrm{div}]$, Time [2s/div].

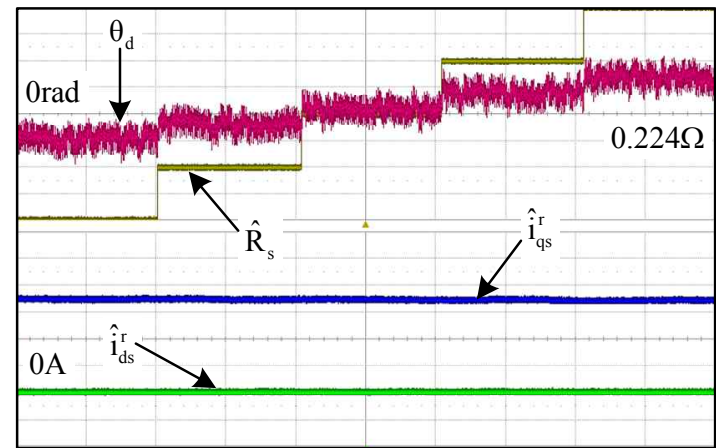

Fig. 14. Angle error by resistance errors with no load at $1000 \mathrm{r} / \mathrm{min}$ : $\theta_{\mathrm{d}}[0.01 \mathrm{rad} / \mathrm{div}], \quad \hat{\mathrm{R}}_{\mathrm{s}}[0.03 \Omega / \mathrm{div}], \hat{\mathrm{i}}_{\mathrm{ds}}^{\mathrm{r}}[2 \mathrm{~A} / \mathrm{div}], \quad \hat{\mathrm{i}}_{\mathrm{qs}}^{\mathrm{r}}[2 \mathrm{~A} / \mathrm{div}]$, Time $[2 \mathrm{~s} / \mathrm{div}]$

smaller than that of the others. Each rotor in Fig. 8 was sequentially assembled and tested with the same stator for observing the angle errors affected by a varied flux linkage. When the d-axis current was regulated to be null, the angle errors due to the inductance errors can be described with:

$$
\theta_{\mathrm{d}} \approx \frac{1}{\lambda_{\mathrm{f}}} \cdot\left(\hat{\mathrm{L}}_{\mathrm{q}}-\mathrm{L}_{\mathrm{q}}\right) \cdot \hat{\mathrm{i}}_{\mathrm{qs}}^{\mathrm{r}} \cdot
$$

The experimental results are shown in Fig. 15. When each inductance error was changed by $2 \mathrm{mH}$, the corresponding angle errors were 0.091 and $0.117 \mathrm{rad}$, respectively in Figs. 15(a) and (b). These results show that the angle error per the
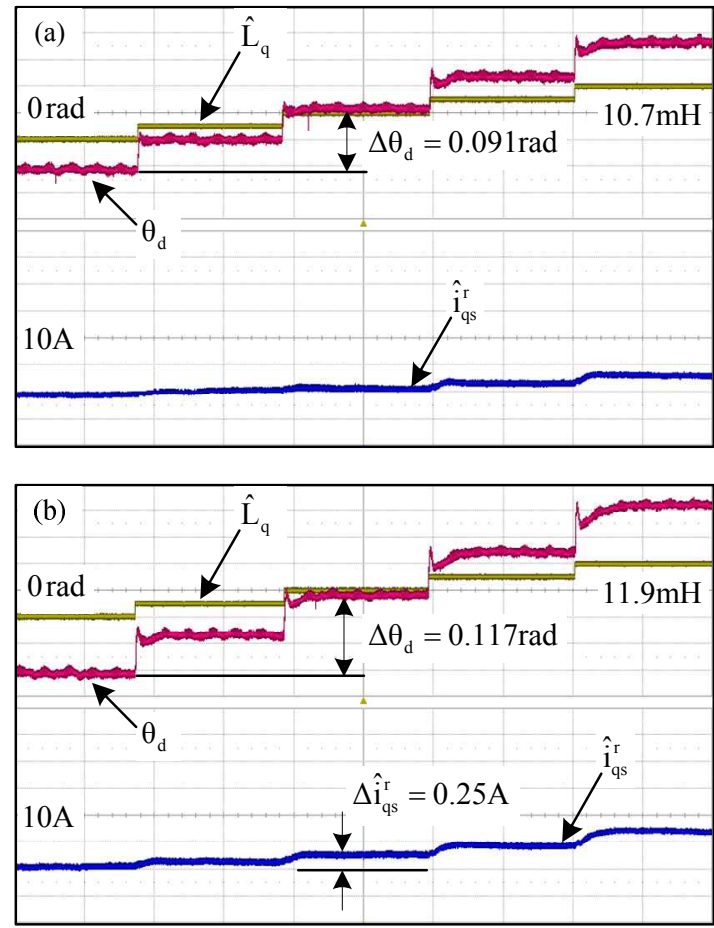

Fig. 15. Angle error changed by flux linkage at 3000r/min, (a) high flux density, (b) low flux density : $\theta_{d} \quad[0.04 \mathrm{rad} / \mathrm{div}]$, $\hat{\mathrm{L}}_{\mathrm{q}}[2 \mathrm{mH} / \mathrm{div}], \hat{\mathrm{i}}_{\mathrm{qs}}^{\mathrm{r}}[0.5 \mathrm{~A} / \mathrm{div}]$, Time [2s/div].

inductance error increased with a decrement of the flux linkage, which coincides with the expectation of (36).

Two features were observed in Figs. 15(a) and (b). One was the slight current increment during the test in Fig. 15(b). Even if angle errors can be altered by the q-axis current as indicated in (36), the variation of the current is only $2.78 \%$ whereas the angle error per the inductance error was changed by $28.57 \%$. In other words, the difference between the angle errors in Figs. 15 (a) and (b) originated mainly from the varied flux linkage.

The other observed feature was that the inductance making the angle error equal to zero was changed from 10.7 to 11.9 $\mathrm{mH}$. When the resultant flux of a PMSM increases, the stator inductance may be decreased [16]. Conversely, the resultant flux of the IPMSM under examination was decreased by the demagnetization. Thus, it can be inferred that the actual inductance was increased in Fig. 15(b) due to the reduced flux.

Every part of the error equation in (31) has been discussed with experimental results. In particular, the angle errors caused by the parameter errors were accurately predicted by the error equation in terms of figures. Although it was not very accurate for predicting the angle errors caused by the non-ideal properties of a driving system, their tendency depending on the operating conditions were credibly explained with the error equation. 


\section{CONCLUSION}

In a sensorless control system, the estimated angle may be inaccurate for many reasons. In this paper, these reasons were comprehensively specified through an error equation. The error equation was so simple that intuitions on angle errors could be easily obtained. In addition to the error-causing factors, the operating conditions that increase angle errors could also be explained. To demonstrate the validity of the equation, several PMSMs driven by a sensorless control method were tested.

The tendency of the predicted angle errors were well matched to that of the measured angle errors for parameter errors. Therefore, the error equation can be utilized to determine the tolerance ranges of parameter variations when a PMSM is designed for a sensorless control system. Furthermore, the compensation priority over the error-causing factors can be appropriately determined by the error equation if the sensorless application of the PMSM is specified.

\section{ACKNOWLEDGMENT}

This work was supported by DMC (Digital Media and Communication) R\&D center, Samsung Electronics Co., Ltd., Korea.

\section{REFERENCES}

[1] B.-H. Bae, S.-K. Sul, J.-H. Kwon, and J.-S. Byeon, "Implementation of sensorless vector control for super-high speed pmsm of turbo-compressor," IEEE Trans. Ind. Appl., Vol. 39, No. 3, pp. 811-818, May/Jun. 2003.

[2] S. Morimoto, K. Kawamoto, and M. Sanada, and Y. Takeda, "Sensorless control strategy for salient-pole pmsm based on extended emf in rotating reference frame," IEEE Trans. Ind. Appl., Vol. 38, No. 4, pp. 1054-1061, Jul./Aug. 2002.

[3] Y.-C. Son, B.-H. Bae, and S.-K. Sul, "Sensorless operation of permanent magnet motor using direct voltage sensing circuit," Conference Record of $37^{\text {th }}$ IAS Annual Meeting, pp. 1674-1678, 2002.

[4] N. Matsui, "Sensorless PM brushless DC motor drives," IEEE Trans. Ind. Electron., Vol. 43, No. 2, pp. 300-308, Apr. 1996

[5] Y. Park, S.-K. Sul, J.-K. Ji, Y.-J. Park, and D.-H. Lee, "Effects of parameter errors on sensorless operation of PMSM," The Transactions of KIPE, Vol. 16, No. 1, pp. 71-78, Feb. 2011.

[6] Y. Inoue, K. Yamada, S. Morimoto, and M. Sanada, "Accuracy improvement of IPMSM sensorless drives with on-line parameter identification," Conference Record of Power Conv. Conference-Nagoya, pp. 860-866, 2007.

[7] N.-S. Park, M.-H. Jang, Jee-Sang Lee, K.-S. Hong, and J.-M. Kim, "Performance improvement of a PMSM sensorless control algorithm using a stator resistance error compensator in the low speed region," Journal of Power Electronics, Vol. 10, No. 5, pp. 485-490, Sep. 2010.

[8] Y. Park, M.S. thesis, Dept. Electrical Eng. and Computer Science, Seoul Nat'l Univ., Seoul, Korea, 2010.

[9] S.-Y. Kim, W. Lee, M.-S. Rho, S.-Y. Park, "Effective dead-time compensation using a simple vectorial disturbance estimator in PMSM drives," IEEE Trans. Ind. Electron., Vol. 57, No. 5, pp. 1609-1614, May 2010.

[10] D. Leggate and R. J. Kerkman, "Pulse-based dead-time compensator for PWM voltage inverters," IEEE Trans. Ind. Electron., Vol. 44, No. 2, pp. 191-197, Apr. 1997.

[11] A. R. Munoz, and T. A. Lipo, "On-line dead-time compensation technique for open-loop PWM-VSI drives," IEEE Trans. Power Electron, Vol. 14, No. 4, pp. 683-689, Jul. 1999.

[12] Y. Park and S.-K. Sul, "A novel method to compensate non-linearity of inverter in sensorless operation of PMSM," conference proceeding, 8th International Conference on Power Electronics - ECCE Asia (ICPE-ECCE Asia), pp. 915-922, 2011.

[13] B.-H. Bae and S.-K. Sul, "A compensation method for time delay of full-digital synchronous frame current regulator of PWM AC drives," IEEE Trans. Ind. Appl., Vol. 39, No. 3, pp. 802-810, May/June 2003.

[14] K. Ogata, "Steady-state errors in unity-feedback control systems," in Modern Control Engineering $4^{\text {th }}$ edition, New Jersey, U.S.A.: Prentice-Hall, Inc., ch. 5-9, p. 288, 2002.

[15] M. A. Johnson and M. H. Moradi, "Some PID control fundamentals," in PID Control: New Identification and Design Methods, London, U.K.: Springer, ch. 2, p. 65, 2005.

[16] J. Hong, D. Hyun, S.-B. Lee, J.-Y. Yoo, and K.-W. Lee, "Automated monitoring of magnet quality for permanent-magnet synchronous motors at standstill," IEEE Trans. Ind. Appl., Vol. 46, No. 4, pp. 1397-1405, Jul./Aug. 2010.

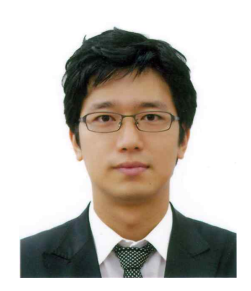

Yongsoon Park received his B.S. and M.S. in Electrical Engineering from Seoul National University, Seoul, Korea, in 2008 and 2010, respectively, where he is currently pursuing a Ph.D. His current research interests include the sensorless drives of electrical machines, and power conversion circuits.

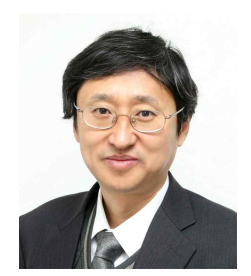

Seung-Ki Sul received his B.S., M.S., and $\mathrm{Ph} . \mathrm{D}$. in Electrical Engineering from Seoul National University, Seoul, Korea, in 1980, 1983, and 1986, respectively. From 1986 to 1988, he was an Associate Researcher in the Department of Electrical and Computer Engineering, University of Wisconsin, Madison. From 1988 to 1990 , he was a Principal Research Engineer with the Gold-Star Industrial Systems Company. Since 1991, he has been a member of the faculty of the School of Electrical Engineering, Seoul National University, where he is currently a Professor. From 2005 to 2007, he was the Vice Dean of Electrical Engineering, Seoul National University. From 2008 to 2011, he was the President of the Korea Electrical Engineering and Science Research Institute (KESRI). His current research interests include the power electronic control of electrical machines, electric/hybrid vehicle and ship drives, and power-converter circuits. 
Jun-Keun Ji received his B.S., M.S., and $\mathrm{Ph} . \mathrm{D}$. in Electrical Engineering from Seoul National University, Seoul, Korea, in 1986, 1988, and 1994, respectively. He was a Research Engineer with KESRI from 1991 to 1994. Since 1994, he has been a faculty member of the Department of Electrical Engineering, Soonchunhyang University, Choongnam, Korea. Currently, he is serving as an Associate Editor of the Journal of Power Electronics, Seoul, Korea. His current research interests include dc/ac machine drives, control of power converters, power quality, UPS, PFC and motion control applications.

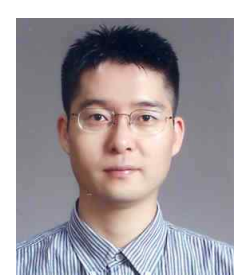

electric machines.
Young-Jae Park received his B.S. and M.S. in Electrical and Electronics Engineering from Yonsei University, Seoul, Korea, in 1998 and 2001, respectively. He is currently with the Digital Media and Communication R\&D Center, Samsung Electronics Company, Suwon, Korea. His current research interests include control theory and its application to 